\title{
A Study on Optimization using Stochastic Linear Programming
}

\author{
Dr. K. L. Muruganantha Prasad, G. L. Lidwin Lucia, S. Mookkan \\ Assistant Professor, Department of Mathematics, H.H.The Rajah's College, Pudukkottai. \\ Assistant Professor, Department of Mathematics Narayanaguru College of Engineering, Mangalumoodu. \\ Associate Professor, Department of Mathematics, PET Engineering College, Valliyoor.
}

\begin{abstract}
The self Help Group (SHG) is group of rural poor who have organized themselves into a group for eradicationof poverty. The members of the group belong to families below the poverty line. This will help the families of occupational groups like agricultural labourers, marginal farmers, designers and artisans marginally above the poverty line, or who may have been excluded from the Below Poverty Line (BPL) list to become members of the Self Help Group. A self help group consists of two categories. One named as magalier thittam and another is non- magalier thittam. The factors of Self help group categories are random in nature. These factors can be handled using stochastic linear programming problem (SLPP). Here the data is collected from Tuticorin district. The optimization technique such as two stage programming and chance constrained programming can be adopted for SLPP. In this paper chance constrained programming (CPP) is used to obtain optimal solution.
\end{abstract}

Keywords: SLPP, CCP, LP, SHG.

Submitted Date 30 May 2013

Accepted Date: 04 June 2013

\section{Need for Stochastic Programming Problem}

Linear programming (LP) constitutes a set of Mathematical Methods specially designed for the modeling of certain kinds of constrained optimization problems. LP problems deal with the optimization of a function which consists of many decision variables. The coefficients and the decision variables of optimization function of a LP model are known in advance. However, for many actual problems, the decision variables may not be known accurately for a variety of reasons. The fundamental reason is that the decision variables may represent information about the future (e.g. product demand or price for a future time period) and simply cannot be known with certainty. So we can apply SLPP. SLPP deals with situations where some or all of the parameters of the optimization problem are described by stochastic (or random or probabilities) variables rather than by deterministic quantities. This paper attempts to find an optimal solution for the following problem.

\section{Optimization Problem dealing with SHG}

- SHG (11) is the group of women either working together or living in the neighbourhood, engaged in similar line of activity ranging from 12-20 members.

- The disabled persons are allowing to this group, the group shall not consist of more than one member from the same family and a person should not be a member of more than one group.

- These groups should operate a group account preferably in their service area bank branch and the group should develop financial management norms covering the loan sanction procedure, repayment schedule and interest rates.

- The group should maintain simple basic records such as Minutes book, Attendance register Loan ledger, General ledger, Cash book, Bank passbook and individual passbooks.

- The members in the group meetings should take all the loaning decisions through a participatory decision making process.

- The group should be able to enhance priorities for the loan applications, fix repayment schedules, fix appropriate rate of interest for the loans advanced and closely monitor the repayment of the loan installments from the borrower.

\section{Details of the Problem}

According to 2001 Census the total population of the study area was 68,263 which are spread over 146 sq.km. The Density of population per Sq.km is 266 . Among 68,263 populations, 33,774 belong to male and 34,489 belong to female. The sexratio of this block is 1,021 . The concerned details of population status in Tuticorin Block is shown in 
Table 1

\begin{tabular}{|c|c|l|}
\hline Serial No & Gender & \multicolumn{1}{|c|}{ Number of Period in \% } \\
\hline 1 & Male & $33,774(49.48)$ \\
\hline 2 & Female & $34,489(50.52)$ \\
\hline & Total & $68,263(100)$ \\
\hline
\end{tabular}

A SHG consists of two categories viz. magalier thittam (part I) and non- magalier thittam (part II). The members of SHG in Tuticorin district are farmers, designers, small shopkeepers, sales men etc. The data (working time required per unit) is collected from designers, who are engaging in embroidery mechanism, designing glass works and fancy works. the items required on different decorative works for each group are not known precisely (as they vary from worker to worker) but are known to follow normal distribution with mean $(\mu)$ and standard deviation $(\sigma)$ as indicated in the table 2

\section{Details of Magalier Thittam and Non Magalier Thittam}

\begin{tabular}{|l|l|l|l|l|}
\hline \multirow{2}{*}{$\begin{array}{l}\text { Typesof } \\
\text { designing }\end{array}$} & \multicolumn{2}{|l|}{ Textiles } & \multicolumn{2}{l|}{$\begin{array}{l}\text { Maximum time available } \\
\text { per week (minutes) }\end{array}$} \\
\cline { 2 - 5 } & Part I Magalier Thittam & $\begin{array}{l}\text { Part II Non Magalier } \\
\text { Thittam }\end{array}$ & \multicolumn{2}{l|}{ Mean } \\
SD \\
\hline Embroidery & $\overline{a_{11}}=7.14 \sigma_{\mathrm{a} 11}=3.18$ & $\overline{a_{12}}=4.16 \sigma_{\mathrm{a} 12}=2.67$ & $\overline{b_{1}}=6000$ & $\sigma_{\mathrm{b} 1}=600$ \\
\hline Design with glass work & $\overline{a_{21}}=5.2 \sigma_{\mathrm{a} 21}=1.9$ & $\overline{a_{22}}=6.4 \sigma_{\mathrm{a} 12}=2.7$ & $\overline{b_{2}}=4800$ & $\sigma_{\mathrm{b} 2}=400$ \\
\hline Fancy work & $\overline{a_{31}}=3.2 \sigma_{\mathrm{a} 31}=1.92$ & $\overline{a_{32}}=3 \sigma_{\mathrm{a} 32}=1.58$ & $\overline{b_{3}}=3600$ & $\sigma_{\mathrm{b} 3}=200$ \\
\hline Profit per Unit & $\mathrm{C}_{1}=180$ & $\mathrm{C}_{2}=250$ & & \\
\hline
\end{tabular}

\section{Stochastic Linear Programming Problem}

A SLPP [5] [6] [8] can be stated as follows:

Maximize or Minimize $\mathrm{f}(\mathrm{x})=\mathrm{c}^{\mathrm{T}} \mathrm{x}$

Subject to

$$
\mathrm{A}_{\mathrm{i}}^{\mathrm{T}} \mathrm{x}=\sum_{j=1}^{n}=\mathrm{a}_{\mathrm{ij}} \mathrm{x}_{\mathrm{j}} \geq \mathrm{b}_{\mathrm{i}}, \mathrm{i}=1,2, \ldots, \mathrm{m}
$$

and $x_{j} \geq 0, j=1,2,3 \ldots . . n$

Where $c_{j} a_{i j}$ and $b_{i}$ are random variables (the decision variables $x_{j}$ are assumed to be deterministic for simplicity) with known probability distributions. Several methods are available for solving the SLPP. However, this paper considers the CCP alone.

\section{Chance Constrained Programming Technique}

The Chance Constrained programming [1] [2] [3] [4] [6] [7] was originally developed by Charnes and Cooper. It belongs to the major approaches for dealing random parameters in optimization problems. Typical areas of application are engineering and finance where uncertainties like product demand, meteorological or demographic conditions, current exchange rates etc.

In CCP, the SLPP is stated as follows:

Maximize or Minimize $\mathrm{f}(\mathrm{x})=\sum_{j=1}^{n}=\mathrm{c}_{\mathrm{j}} \mathrm{x}_{\mathrm{i}}$

Subject

and

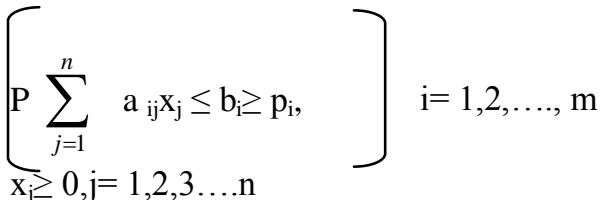

Where $c_{j} a_{j i}$ and $b_{i}$ are random variables and $p_{i}$ are specified probabilities.

We shall first consider special cases where only $c_{j}$ or $a_{j i}$ or $b_{i}$ are random variables before considering the general case in which $c_{j} a_{j i}$ and $b_{i}$ and $b_{i}$ are all random variables. We shall further assume that all the random variables are normally distributed with known mean and standard deviation.

When $\mathbf{c}_{\mathrm{j}}, \mathbf{a}_{\mathrm{ji}}, \mathbf{b}_{\mathbf{i}}$ are random variables: As the random variables $c_{\mathrm{j}}, \mathrm{j}=1,2 \ldots \mathrm{n}$, appear only in the objective function, the new objective function is

Maximize or Minimize $\mathrm{F}(\mathrm{x})=\mathrm{k}_{1} \bar{f}+\mathrm{k}_{2} \sqrt{\operatorname{var}(f)}$

subject $\mathrm{p}\left[\mathrm{h}_{\mathrm{i}} \leq 0\right] \geq \mathrm{p}_{\mathrm{i}} \mathrm{i}=1,2 \ldots, \mathrm{m}$ 
Where $\bar{f}=\sum_{j=1}^{n} \bar{c}_{\mathrm{j}} \mathrm{x}_{\mathrm{j}}, \mathrm{k}_{1}$ and $\mathrm{k}_{2}$ are nonnegative constants whose values indicate the relative importance of $\bar{f}$ and standard deviation of $\mathrm{f}$ for minimization or maximization.

$\mathrm{h}_{\mathrm{i}}$ is anew random variables defined as

$\mathrm{h}_{\mathrm{i}}=\sum_{j=1}^{n} \mathrm{a}_{\mathrm{ij}} \mathrm{x}_{\mathrm{j}}-\mathrm{b}_{\mathrm{i}}=\sum_{k=1}^{n+1} \mathrm{q}_{\mathrm{ik}} \mathrm{y}_{\mathrm{k}} \mathrm{q}_{\mathrm{ik}}=\mathrm{a}_{\mathrm{ik}} \mathrm{q}_{\mathrm{i}, \mathrm{n}+1}=\mathrm{b}_{\mathrm{i}} \quad \mathrm{y}_{\mathrm{k}}=\mathrm{x}_{\mathrm{k},} \mathrm{k}=12, . . \mathrm{y}_{\mathrm{n}+1}=-1$

it will follow normal distribution, the mean and the Variance of $h_{i}$ are given by

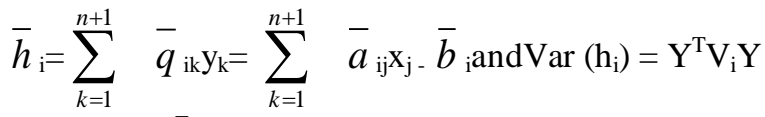

$\mathrm{y}=\left\{\begin{array}{l}\operatorname{Var}\left(\mathrm{h}_{\mathrm{i}}\right)=\mathrm{Y}^{\mathrm{T}} \mathrm{V}_{\mathrm{i}} \mathrm{Y} \\ \mathrm{y}_{1} \\ \mathrm{y}_{2} \\ \mathrm{y}_{3} \mathrm{~V}_{\mathrm{i}}= \\ \mathrm{y}_{\mathrm{n}+1}\end{array}\right\} \cdot\left[\begin{array}{llll} & & & \\ \operatorname{var}\left(\mathrm{q}_{\mathrm{i} 1}\right) & \operatorname{Cov}\left(\mathrm{q}_{\mathrm{i} 1}, \mathrm{q}_{\mathrm{i}}\right) & . . & \operatorname{Cov}\left(\mathrm{q}_{\mathrm{i} 1}, \mathrm{q}_{\mathrm{i}, \mathrm{n}+1}\right) \\ \operatorname{Cov}\left(\mathrm{q}_{\mathrm{i} 2}, \mathrm{q}_{\mathrm{i} 1}\right) & \operatorname{var}\left(\mathrm{q}_{\mathrm{i} 2}\right) & . . & \operatorname{Cov}\left(\mathrm{q}_{\mathrm{i} 2,}, \mathrm{q}_{\mathrm{i}, \mathrm{n}+1}\right) \\ & . & . . & \\ \operatorname{Cov}\left(\mathrm{q}_{\mathrm{i}, \mathrm{n}+1}, \mathrm{q}_{\mathrm{i} 1}\right) & \operatorname{Cov}\left(\mathrm{q}_{\mathrm{i}, \mathrm{n}+1,}, \mathrm{q}_{\mathrm{i} 2}\right) . . & \operatorname{var}\left(\mathrm{q}_{\mathrm{in}+1}\right)\end{array}\right]$

This can be written as

$\operatorname{Var}\left(\mathrm{h}_{\mathrm{i}}\right)=\left[\sum_{k=1}^{n+1} \mathrm{x}_{k}^{2} \operatorname{Var}\left(\mathrm{a}_{\mathrm{ik}}+2\right) \sum_{i=k+1}^{n} \mathrm{x}_{\mathrm{k}} \mathrm{x}_{1} \operatorname{Cov}\left(\mathrm{a}_{\mathrm{ik}}, \mathrm{a}_{\mathrm{i} 1}\right)+\operatorname{Var}\left(\mathrm{b}_{\mathrm{i}}\right)-2 \sum_{k=1}^{n}\right] \mathrm{x}_{\mathrm{k}} \operatorname{Cov}\left(\mathrm{a}_{\mathrm{ik}}, \mathrm{b}_{\mathrm{i}}\right)$

Thus the constraints in (2.1.2) can be restated as

$\mathrm{p}\left[\frac{h_{i}-\overline{h_{i}}}{\sqrt{\operatorname{Var}\left(h_{i}\right)}} \leq \frac{\overline{-h_{i}}}{\sqrt{\operatorname{Var}\left(h_{i}\right)}} \geq \mathrm{p}_{i}\right] 1=1,2 \ldots, \mathrm{m}$

The constraints of equation (2.1.3) can be stated as

$\phi \quad\left(-\frac{\overline{h_{i}}}{\sqrt{\operatorname{Var}\left(h_{i}\right)}}\right) \geq \phi\left(\mathrm{e}_{\mathrm{i}}\right)$

The SLPP can be stated as

Maximize or Minimize $\mathrm{F}(\mathrm{X})=\mathrm{k}_{1} \sum_{j=1}^{n} \bar{c}_{\mathrm{j}} \mathrm{x}_{\mathrm{j}}+\mathrm{k}_{2} \sqrt{X^{T} V X}, \mathrm{k}_{1} \geq 0, \mathrm{k}_{2} \geq 0$

Subject to

$$
\left.\bar{h}_{\mathrm{i}}+\mathrm{e}_{\mathrm{i}} \sqrt{\operatorname{Var}(h} \mathrm{i}\right) \leq 0, \mathrm{i}=1,2, \ldots, \mathrm{m}
$$

and

$$
x j \geq 0, j=1,2 \ldots, n
$$

\section{Implementation of this Technique}

By denoting the number of SHG part I and part II manufactured per week as $x_{1}$ and $x_{2}$ respectively, the problem can be stated as follows:

Maximize

$$
\mathrm{f}=\mathrm{k}_{1}\left(180 \mathrm{x}_{1}+200\right) \mathrm{k}_{2} \sqrt{400 x_{1}^{2}+2500 x_{2}^{2}}
$$

Subject to constraints

$7.14 \mathrm{x}_{1}+4.6 \mathrm{x}_{2}+2.33 \sqrt{10.11 x_{1}^{2}+7.13 x_{2}^{2}+360000}-6000 \leq 0$
$5.2 \mathrm{x}_{1}+6.2 \mathrm{x}_{2}+2.33 \sqrt{3.61 x_{1}^{2}+7.29 x_{2}^{2}+160000}-4800 \leq 0$ 
$3.2 \mathrm{x}_{1}+3 \mathrm{x}_{2}+2.33 \sqrt{3.686 x_{1}^{2}+2.49 x_{2}^{2}+40000}-3600 \leq 0$

and $\mathrm{x}_{1} \geq 0, \mathrm{x}_{2} \geq 0$

This problem can be solved by using any of the nonlinear programming methods. Here the Kuhn Tucker conditions are followed.

$$
\begin{aligned}
& \delta f \quad \delta h \\
& -\lambda 1-=0 \\
& \delta x_{1} \quad \delta x_{1} \\
& \delta f \quad \delta h \\
& -\lambda 2-=0 \\
& \begin{array}{llll}
\delta & x_{2} & \delta & x_{2}
\end{array} \\
& \delta f \quad \delta h \\
& -\lambda 3-=0 \\
& \begin{array}{llll}
\delta & x_{3} & \delta & x_{3}
\end{array} \\
& \lambda_{\mathrm{i}} \mathrm{h}^{\mathrm{i}}=0, \mathrm{~h}^{\mathrm{i}} \leq 0, \lambda_{\mathrm{i}} \geq 0
\end{aligned}
$$

$\lambda$ is the Lagrangian multipliers.

The Kuhn Tucker conditions related to the problem is shown as Maximize

$\mathrm{f}-\mathrm{k}_{1}\left(180 \mathrm{x}_{1}+200 \mathrm{x}_{2}\right)+\mathrm{k}_{2}$

subjects to constraints

$$
\begin{aligned}
& \mathrm{h}^{1}(\mathrm{x})=7.14 \mathrm{x}_{1}+4.6 \mathrm{x} 2+2.33 \sqrt{10.11 x_{1}^{2}+7.13 x_{2}^{2}+360000}-6000 \leq 0 \\
& \mathrm{~h}^{2}(\mathrm{x})=5.2 \mathrm{x}_{1}+6.2 \mathrm{x}_{2}+2.33 \sqrt{3.61 x_{1}^{2}+7.29 x_{2}^{2}+160000}-4800 \leq 0 \\
& \mathrm{~h}^{3}(\mathrm{x})=3.2 \mathrm{x}_{1}+3 \mathrm{x}_{2}+2.33 \sqrt{3.686 x_{1}^{2}+2.49 x_{2}^{2}+40000}-3600 \leq 0
\end{aligned}
$$

and $\quad \mathrm{x}_{1} \geq 0, \mathrm{x}_{2} \geq 0$

Hence, the solution of the SLPP is obtained as $\mathrm{x}_{1}=128$ and $\mathrm{x}_{2}=173$. The maximization yields the two categories of magalier thittam \& non magalier thittam are 96182.61 .

\section{Conclusion and Suggestions}

In this paper, SLPP is used to optimize the number of groups in SHGof Tuticorin district. To solve the SLPP, the CCP is adopted and theoptimal solution is obtained. This chance constrained programmingpermits the constraints to be violated by a specified probability; whereas other techniques like two stage programming technique do not permit any constraint to be violated. In this aspect, this technique)is suitable for various aspects (like production, demand...).

\section{References}

[1] Li P., Arellano-Garcia H., Wozny G., "Chance Constrained Programming Approach to Process Optimization under Uncertainty", Computers and Chemical Engineering 32,25-45,2008.

[2] CHARNESA, and W.W. COOPER", Chance Constrained Programming,"Management Science, Vol. 5, 1959 , pp. 73-79.

[3] Cigdem Z. Gurgur a; James T. Luxhoj," Application of Chance-Constrained Programming to Capital Rationing Problems With Asymmetrically Distributed Cash. Flows and Available Budget,"The Engineering Economist, Vol. 48, 2003.

[4] Harvey ARELLANO-GARCIA," Chance ConstrainedOptimization of Process Systems under Uncertainty".

[5] R. Jagannathan , Chance-Constrained Programming with Joint Constraints, http://www.jstor.org/action 1974

[6] Kantiswarup, P. K. Gupta and Man Mohan,"Operations research", Sultan Chand \&Sons, New Delhi, 1993.

[7] S. S. RAO, Optimization theory and applications, Wiley, New York, 1992

[8] RENE HENRION,"Introduction to Chance -Constrained Programming"www.stoprog.org.

[9] Suvrajeet Sen and Julia L. Higle, "An Introductory Tutorial on Stochastic LinearProgramming Models", Programming Stochastic Tutorial.

[10] H. A. Taha, Operations research: an introduction, Macmillan, New York, 1971

[11] EDA Rural Systems Pvt Ltd,"Self Help Groups in India A study of the lights and shades", APMAS(Andhra Pradesh Manila Abhivruddhi Society). 